\title{
PHOTO-SYNTHESIS OF THE SUGAR CANE MOSAIC PLANT
}

Melville T. Cook, Chief of the Division of Plant Pathology

The symptoms of the mosaic diseases of many plants and the symptoms of plants with similar diseases such as "peach yellows" and "little peach" indicate a reduced or disturbed photo-synthesis, which usually results in a reduced growth or death or both.

References have been made in a number of papers on mosaic diseases to the amount of starch in the chlorotic cells of diseased plants but so far as the writer has been able to determine no speeial studies have been made on the relationship of the disease to photo-synthesis or any comparative studies on the photo-synthetic action of normal plants and those infected with mosaic. It is the purpose of this paper to give some of the accumulated data bearing on the photo-synthetic activities of some mosaic plants and the results of our own studies on the photo-synthesis of mosaic of sugar cane as compared with healthy plants.

The white, yellowish and light-green areas which are characteristic of mosaic plants indicates a reduction in amount or absence of chlorophyll, or an abnormal condition of same and most of the references in the literature indicate that this is true. Any of these conditions would necessarily interfere with the photo-synthetic activities of the plant. The limited references to this phase of the subject may be summarized as follows: In 1899 Koning (8) who was making a study of tobaceo mosaic called attention in some cases to the disorganization of the chloroplasts. In 1900 Woods (12) reported that the light-colored areas of both tobaceo and tomato plants infected with mosaic contained more than the normal amount of starch, which is contrary to the findings of most workers. And in 1902 (13) the same author makes this statement:

"the disease is not primarily a disease of the chloroplasts; as Beijerinck thought, is evident from the fact that in the less pronounced cases the chloroplasts, though fewer in number, are not decreased in size or activity.',

In 1903 Iwanowsky (7) reported that when the leaves of mosaie tcbacco plants were young, the chloroplast in the light areas were yellowish and searcely reacted to the starch tests, but that later the chloroplast contained a large amount of starch. This indicates that the plant passes through an abnormal condition from which it partly or completely recovers so far as the photo-synthetic processes are 
concerned. In the same year Bouygues (2) reported the disappearance of the cell contents in the light areas of mosaic tobacco leaves. In 1910 Westerdyk (11) reported that in the case of tomatoes, the chloroplast in the cells in the yellow areas were smaller than those in the green areas and contained very little starch. In 1913 Melchers (9) reported on tomato mosaic as follows:

"No difference was detected in the number or size of the chloroplast in the yellow and green areas. That they were well supplied with starch was apparent."

The same author in the same year reported on potato mosaic as follows :

"The chloroplast throughout the yellow regions in the living material were a pale yellowish-green but cositained considerable starch.',

In 1918 Artschwager (1) reported an accumulation of starch in the leaves of leaf-roll potatoes. In this same year True and Hawkins (10) conducted chemical studies on spinach which indicated that both starch and sugar content were greater in diseased than healthy plants. Their results are summarized as follows:

"It appears that in spinach-blight the process of carbo-hydrate manufacture is not inhibited although it may be retarded.",

These studies were chemical and not eytological and were made on diseased plants as compared with healthy plants; but not on chlorotic areas as compared with normal areas. It is doubtful if these results should be placed in the same category as the others which are referred to in this paper. In 1921 the author (3) of this paper reported the results of studies on "peach yellows" and "little peach". These 'studies indicated that the translocation of starch was partly or completely inhibited in the diseased trees. The accumulation of starch no doubt explains the thick, leathery texture ef old leaves infected with either of these diseases. In 1922 Dickson (6) reported that in tobacco-mosaic leaves there was a reduction in the number of chloroplasts which in the case of the palisade cells were irregularly arranged in the lower half of the cells. In 1925 the author of this paper expressed the opinion as a result of the study of the histology and cytology of mosaic sugar cane (4) that the chloroplasts did not undergo disintegration but that their development was inhibited. In 1927 the writer of this paper reaffirmed (5) his opinion that the chloroplasts of the chlorotic areas did not undergo degeneration as a result of the disease but that they were undeveloped from the beginning and tended to become normal in appearance with age and exposure to sunlight. 
A careful review of the data presented in the papers bearing on this subject, show some differences of opinion concerning the contents of the cells, especially with reference to the presence and character of the chloroplasts, but the paper on "peach yellows" and "little peach" by the writer (3) of this paper is the only one that the author has been able to find in which there is any effort to correlate the presence or absence of carbohydrates with the photosynthetic activity of the plant.

During the past three years the writer of this paper has been making studies on the photo-synthetic activity of sugar-cane plants infected with mosaic as compared with normal plants. These studies were restricted to the microscopic examination of plants collected between 5 and $6 \mathrm{~A}$. M. and between 2 and 3 P.M. The tissues were treated in various ways to bring out the desired information. The plants for study were grown within 100 feet of the laboratory. In some cases the studies were made immediately on free-hand sections while in other cases the sections were prepared by longer processes.

These studies showed that the normal plants and the green areas of the diseased plants performed their proto-synthesis in the normal manner and showed a large amount of starch in the afternoon and very little in the morning, while the white and light green or yellowish areas showed a small amount of starch in the afternoon and practically none in the early morning (Figs. 1 to 4 ). It was very evident that the starch-forming power of the mosaic cane was reduced in proportion to the amount of infection while the power of translocation was practically unimpaired. This is the reverse to the findings of the writer in the case of the "peach yellows" and "Iittle peach" in which the cells of the diseased leaves are filleat with starch but in which the translocation is greatly reduced or completely inhibited. These studies indicate that we may have two types of disease; the one generally represented by the various mosaics in which the photo-synthetic activities are greatly reduced. The second which is represented by "peach yellow" and "little peach" in which starch is formed in the leaves but not transported to other parts of the plant, the result being that the leaves become hard and leathery. The accumulation of starch in the leaves of "leaf roll" potatoes which has been referred to by Artschwager and the leather texture of the leaves of such plants, may indicate that the "leaf roll" of potatoes should be classed with the "peach yellows" and "little peach". These studies also showed that the old leaves of sugar cane infected with mosaic produced more starch than the young leaves of the same plants. This is no doubt due to the 
fact that the chloroplasts in chlorotic areas of mosaic plants tend to increase in size and number with the age of the leaf as indicated in another paper by the author (5).

\section{LITERATURE}

1. Artschwager, Ernst F. Histological Studies on the Potato Leaf Roll. Journal of Agricultural Research, 15:559-570 (1918).

2. Bourgues, H. Sur la Nielle des feuilles du tobac. Competes Rendus, 137 : 103-1305 (1903).

3. Coок, Mer. T. Peach Yellows and Little Peach. Botanical Gazette, 72: 250-254 (1921).

4. - Histology and Cytology of Sugar-Cane Mosaic. The Journal of the Department of Agriculture of Porto Rico, $9: 5-27$ (1925).

5. - The Effects of Mosaic on the Content of the Plant Cell. The Journal of the Department of Agriculture of Porto Rico, 10 :

6. Dickson, B. T. Studies Concerning Mosaic Diseases. Macdonald College. Technical Bulletin No. 2 (1922).

7. Iwanowski, Dm. Ueber die Mosaikkranheit der Tobakspflanze. Zeitscherf. f. Pflanzerkt, 13:1-40 (1903).

8. Koning, C. T. Die Flerken-oder Mosaikkranheit des Hollandschen Tobaks. Zeitscherf. f. Pflanzerkt, 9:65-80 (1899).

9. Melchers, Leo E. The Mosaic Disease of the Tomato and Relanted Plants. Ohio Naturalist 13:149-173 (1913).

10. True, Rodney H. \& Hawkins, Lon A. Carbohydrate Production in Healthy and Blighted Spinach. Journal of Agricultural Research, $15: 381-384$ (1918).

11. Westerdjk, JoHa. Die Mosaikkranheit der Tomoten. Mededeelingen uit het Phytopathologisch Laboratorium, "Willie Commelin Scholten", Amsterdam. Maart, pp. 1-19 (1910).

12. Woods, A. F. Inhibiting Action of Oxidase upon Diastase: Science n.s. 11:17-19 (1900).

13. — Observations on the Mosaic Disease of Tobacco. U. S. Dept. of Agri., Bureau of Plant Industry, Bull. 18 (1902).

\section{EXPLANATION OF PLATES}

Fig. 1.-Cross section of leaf of normal plant at 3:00 P. M. Fig. 2.-Cross section of leaf of mosaic plant at 3:00 P. M. Fig. 3.-Cross section of leaf of normal plant at 6:00 A. M. Fig. 4.-Cross section of leaf of mosaic plant at 6:00 A. M. 

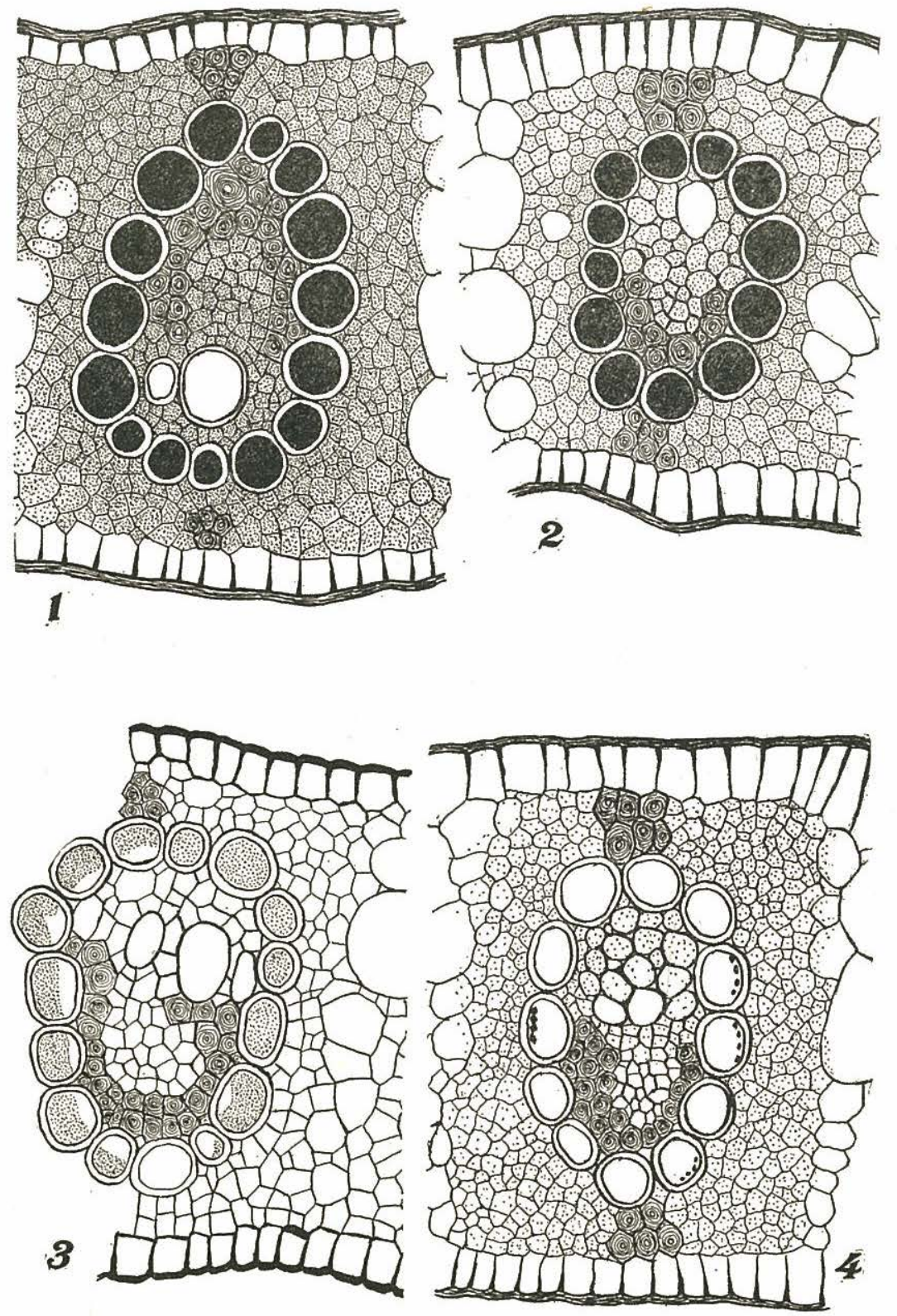